\title{
Enantioselective cyanation of benzaldehyde: An asymmetric polymeric catalyst in a microreactor
}

\author{
Stina Lundgren, ${ }^{a}$ Henrik Ihre, ${ }^{b}$ and Christina Moberg ${ }^{* a}$ \\ ${ }^{a}$ KTH School of Chemical Science and Engineering, Organic Chemistry, SE 10044 Stockholm, \\ Sweden ${ }^{b}$ GE Healthcare, Björkgatan 30, SE 75184 Uppsala, Sweden \\ E-mail: kimo@kth.se
}

\section{Dedicated to Professor Torbjörn Norin}

\begin{abstract}
A chiral salen ligand containing a carboxylic acid group was attached to macroporous monosized polystyrene-divinylbenzene beads grafted with (4-hydroxybutyl)vinyl ether groups. A Ti(IV) complex of the beads was used for enantioselective cyanations of benzaldehyde using trimethylsilyl cyanide and acetyl cyanide as cyanide sources using both conventional batch techniques and a microreactor.
\end{abstract}

Keywords: Cyanation, microreactors, polymer-supported, salen, titanium

\section{Introduction}

Polymer-supported metal catalysts have advantages for use in enantioselective synthesis since the metal complexes can be recovered and occasionally reused. ${ }^{1}$ Solid phase catalysts are particularly advantageous for use in continuous flow processes since, in addition to simplified product purification, the presence of an excess of the catalyst in the reaction chamber may more easily drive reactions to completion. ${ }^{2}$ The use of flow through reactors, in particular microreactor technology, for applications within the field of organic synthesis offers distinct advantages over conventional laboratory techniques. ${ }^{3}$ Reactions performed in a continous flow often provide higher yields and selectivities than those performed in batch operations. The lower consumption of reagents and consumables and decreased production of waste resulting from miniaturization are of obvious interest for economic, safety and environmental reasons. It is therefore not surprising that microfluidic devices are gaining increased attention for organic synthesis with applications ranging from combinatorial chemistry and drug discovery ${ }^{4}$ to industrial production. ${ }^{5}$

Examples of enantioselective syntheses in microreactors are still rather few, ${ }^{6}$ and although some metal-catalyzed reactions have been performed in microfluidic devices, ${ }^{7}$ only a limited 
number of asymmetric metal-catalyzed reactions have been reported. ${ }^{8}$ Such applications are expected to increase since microfluidic devices should be ideal not only for the preparation of compound libraries but also for high throughput optimization of catalytic reactions: a catalytic system usually has to be modified for each reaction and even for each substrate undergoing reaction, requiring a large number of small scale reactions under variable conditions. A particular challenge involves integrating high throughput synthesis and analysis on a single chip. To our knowledge, this has been achieved only in a single case where enzyme mutants were used for hydrolytic kinetic resolution of a racemic epoxide on a chip containing a chiral selector for substrate and product separation and using fluorescence detection. ${ }^{7}$

We have employed microreactors for enantioselective metal-catalyzed cyanations of prochiral aldehydes using both electroosmotic ${ }^{8}$ and pressure driven flows. ${ }^{8 c}$ In the latter case, ketonitriles were used as cyanide sources, for the first time giving direct access to highly enantioenriched acylated cyanohydrins. A high throughput enzymatic method was developed for the analysis of O-acylated cyanohydrins obtained using $\alpha$-ketonitriles as cyanation reagents. ${ }^{8 c, 10}$ Although synthesis and analysis were not integrated to yield a true lab-on-a-chip, the operations were performed in succession thereby providing a highly efficient tool for catalyst optimization. In this communication, we describe the preparation and use of a solid supported chiral catalyst prepared from a macroporous polymeric bead and its use in the synthesis of O-silylated and Oacylated cyanohydrins both in conventional batch operations and within a microreactor.

\section{Results and Discussion}

The dimeric titanium(IV) salen complex 1 was introduced by Belokon, North and co-workers for cyanation of aldehydes using trimethylsilyl cyanide ${ }^{11}$ and ethyl cyanoformate. ${ }^{12}$ We used the same Lewis acid catalyst together with a Lewis base for the addition of ketonitriles to prochiral aldehydes and obtained highly enantioenriched O-acylated cyanohydrins in one step in a perfectly atom-economic reaction. ${ }^{13}$ Since the catalyst consists of two parts, a Lewis acid and a Lewis base, which can be independently varied, high throughput optimization using microreactor technology is a highly suitable option.

For the preparation of a polymer-supported catalyst, phenolic ligand $2 \mathbf{a}^{14}$ was synthesized by condensation of $(R, R)$-1,2-diaminocyclohexane with 4,6-di-tert-butylsalicyl aldehyde and 4hydroxy-4-tert-butylsalicyl aldehyde. Transformation to $\mathbf{2 b}$ using a published procedure ${ }^{15}$ afforded a chiral ligand containing an appropriate handle for attachment to a hydroxyfunctionalized polymer.

As solid support we selected $15 \mu \mathrm{m}$ mono-sized macroporous divinylbenzene beads modified with a hydrophilic coating. The surface coating of the hydrophobic polystyrene was performed by a radical mediated grafting of (4-hydroxybutyl)vinyl ether, from the residual vinyl groups at the surface of the divinylbenzene backbone. ${ }^{16}$ This resulted in rigid beads with mechanical properties suitable for use in a flow reactor and with a multitude of reactive hydroxy groups 
linked via flexible spacer arms, ensuring high accessibility of the catalytic sites. The small bead size $(15 \mu \mathrm{m})$ and the high readily accessible surface area also make this medium suitable for devices having smaller dimensions than the one actually employed for the present application.
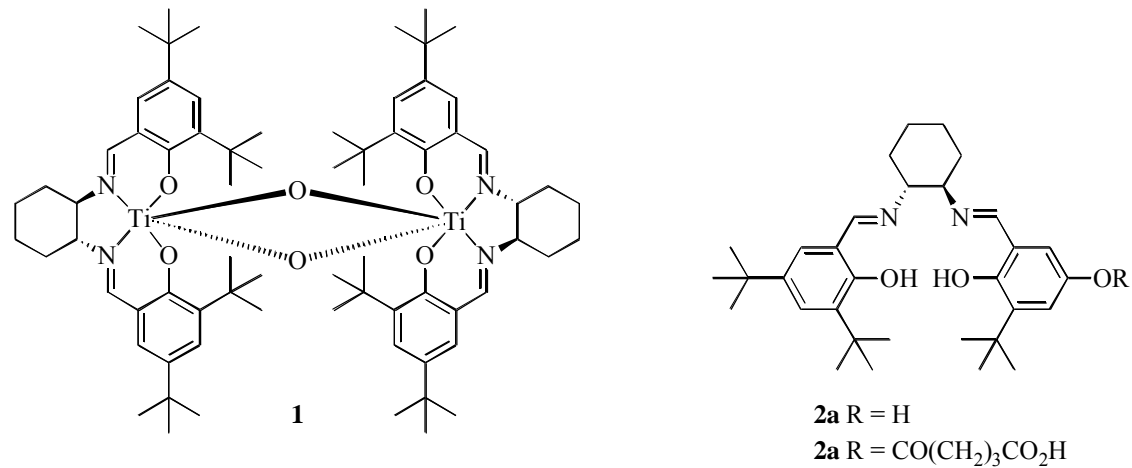

The salen ligand $\mathbf{2 b}$ was conveniently attached to the hydroxy-functionalized divinylbenzene bead by ester bond formation using DCC/DMAP (Scheme 1). The titanium complex was prepared using an analogous procedure to that used for the monomeric ligand. Thus, the polymeric ligand was reacted with with $\mathrm{TiCl}_{4}$ in dichloromethane followed by the addition of a phosphate buffer ( $\mathrm{pH}$ 7). After removal of solvent and washing a bright yellow solid, 4, was obtained. It is unknown to what extent dimeric complexes are formed on the polymer.

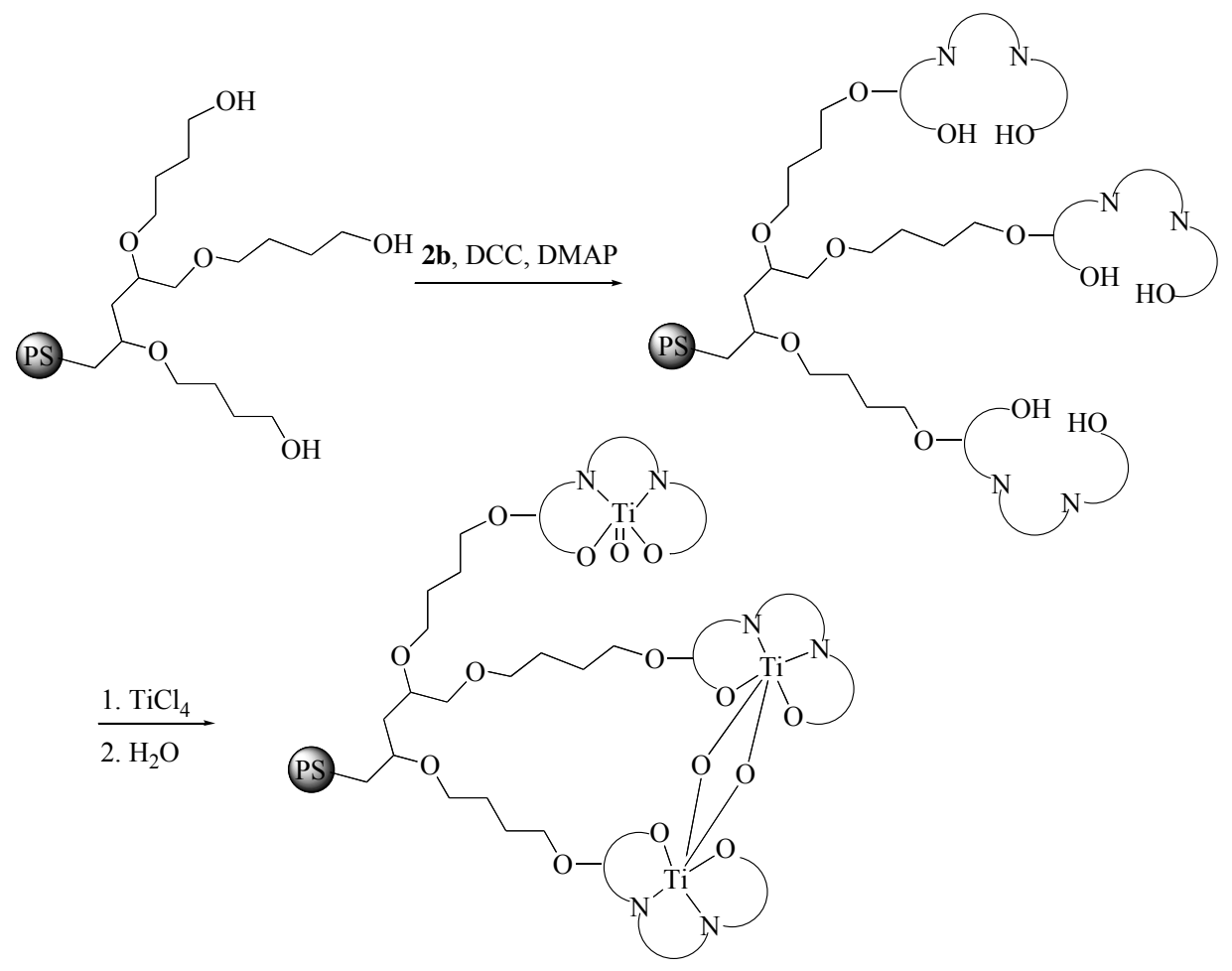

Scheme 1. Synthesis of the polymeric Ti-salen complex 4. 
Catalytic reactions were first performed using normal batch procedures. Reactions were run at room temperature to facilitate comparisons with reactions using microreactor. Trimethylsilyl cyanide and benzaldehyde afforded TMS-protected cyanohydrin 5a with $91 \%$ conversion and with $73 \%$ ee within 3 hours at room temperature in the presence of 4 . Use of acetyl cyanide in place of trimethylsilyl cyanide gave $5 \mathbf{b}$ with $39 \%$ conversion after 3 hours and with $68 \%$ ee when 4 was employed as catalyst together with $\mathrm{Et}_{3} \mathrm{~N}$. Lowering the temperature to $-20{ }^{\circ} \mathrm{C}$ resulted in increased enantioselectivity. In the addition of TMSCN to benzaldehyde a product with $84 \%$ ee was obtained and the addition of acetylcyanide gave 5 b with $84 \%$ ee and $62 \%$ conversion within 20 hours. The polymeric catalyst could be reused up to five times without any observed deterioration of reactivity or selectivity.

Next, a microreactor with an inner dimension of $3 \mathrm{~mm}$ in diameter and with a total volume of $70 \mu \mathrm{L}$ and a $2 \mu \mathrm{m}$ frit obtained from Omnifit was charged with polymer 4 . The liquid was mobilized by applying a mechanical flow using a syringe pump.

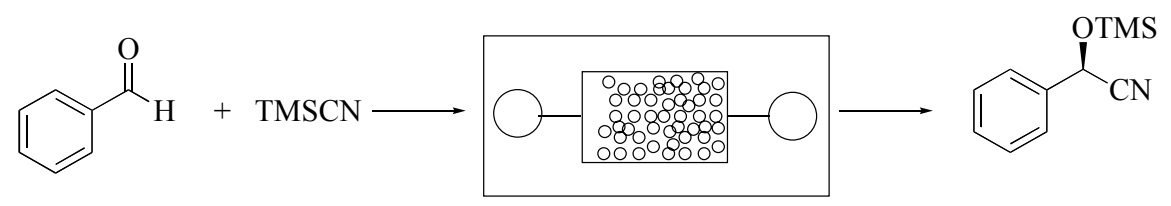

Figure 1. The microreactor with a filter containing the polymeric Ti-salen catalyst 4.

First we studied cyanation of benzaldehyde using TMSCN as cyanide source. The conversion increased with decreased flow rate, as expected from the longer contact time between the catalyst and the reactants (Table 1). The polymeric catalyst could be reused and the system was stable. TMS-protected mandelonitrile was obtained with up to $72 \%$ ee and in $92 \%$ conversion at a flow rate of $0.8 \mu \mathrm{L} / \mathrm{min}$ (entry 4 ). The selectivity was barely not effected by variations in flow rate.

Table 1. Cyanation of benzaldehyde by TMSCN catalyzed by 4 in the micro reactor ${ }^{\mathrm{a}}$

\begin{tabular}{lllll}
\hline Entry & Flow $(\mu \mathrm{L} / \mathrm{min})$ & \% Conv. $^{\mathrm{b}}$ & $\% \mathrm{ee}^{\mathrm{c}}$ & Abs. Conf. $^{\mathrm{d}}$ \\
\hline 1 & 2 & 32 & 70 & $S$ \\
2 & 1 & 79 & 72 & $S$ \\
3 & 1 & 82 & 71 & $S$ \\
4 & 0.8 & 92 & 72 & $S$ \\
\hline
\end{tabular}

${ }^{\mathrm{a}}$ Reaction conditions: 1.2 equiv. TMSCN, $20-25{ }^{\circ} \mathrm{C} .{ }^{\mathrm{b}}$ Determined by GC-MS. ${ }^{\mathrm{c}}$ Determined by chiral GC. ${ }^{\mathrm{d}}$ Assigned by comparing the sign of optical rotation with literature data. ${ }^{17}$

Next, acetyl cyanide was employed as cyanide source in cyanation of benzaldehyde catalyzed by 4 and $\mathrm{Et}_{3} \mathrm{~N}$ (Table 2). A solution of acetyl cyanide, benzaldehyde and $\mathrm{Et}_{3} \mathrm{~N}$ in dichloromethane was flowed trough the polymeric catalyst. In this case, the enantioselectivity increased with decreased flow rate. This can be explained by an unselective background reaction 
catalysed by $\mathrm{Et}_{3} \mathrm{~N}$ taking place in absence of the chiral complex. The cyanation employing acetyl cyanide is slower than that with TMSCN and conversions were therefore low, even at low flow rates. As expected, an increased amount of the polymeric $\mathrm{Ti}$ complex resulted in higher conversions (entries 5-7).

Table 2. Cyanation of benzaldehyde by acetyl cyanide catalyzed by 4 in the micro reactor ${ }^{\mathrm{a}}$

\begin{tabular}{lllll}
\hline Entry & Flow $(\mu \mathrm{L} / \mathrm{min})$ & \% Conv. & \% ee & Abs. Conf. $^{\mathrm{d}}$ \\
\hline $1^{\mathrm{e}}$ & 1 & 35 & 32 & $\mathrm{~S}$ \\
$2^{\mathrm{e}}$ & 0.8 & 27 & 40 & $\mathrm{~S}$ \\
$3^{\mathrm{e}}$ & 0.8 & 29 & 39 & $\mathrm{~S}$ \\
$4^{\mathrm{e}}$ & 0.6 & 25 & 69 & $\mathrm{~S}$ \\
$5^{\mathrm{f}}$ & 1 & 66 & 31 & $\mathrm{~S}$ \\
$6^{\mathrm{f}}$ & 0.8 & 50 & 39 & $\mathrm{~S}$ \\
$7^{\mathrm{f}}$ & 0.6 & 48 & 70 & $\mathrm{~S}$ \\
\hline
\end{tabular}

${ }^{\mathrm{a}}$ Reaction conditions: 2 mol\% $\mathrm{Et}_{3} \mathrm{~N}, 2$ equiv. acetyl cyanide, $20-25{ }^{\circ} \mathrm{C}$. ${ }^{\mathrm{b}}$ Determined by GC-MS.

${ }^{\mathrm{c}}$ Determined by chiral GC. ${ }^{\mathrm{d}}$ Assigned by comparing the sign of optical rotation with literature data. $^{18}$ e $20 \mathrm{mg},{ }^{\mathrm{f}} 40 \mathrm{mg}$ polymeric Ti-salen complex 4.

The polymeric catalyst 4 within the micro reactor could be reused several times without decrease in selectivity or reactivity. Consequently, the reaction outcome did not change with time.

\section{Conclusions}

A process for asymmetric catalysis using a reusable catalyst based on a macroporous mono-sized divinylbenzene bead in a pressure-driven microreactor has been developed. The enantioselectivities observed are comparable to those obtained in batch reactions. This methodology has high potential for high throughput screening of catalytic performance.

\section{Experimental Section}

General Procedures. Benzaldehyde, $\mathrm{CH}_{2} \mathrm{Cl}_{2}$ and $\mathrm{Et}_{3} \mathrm{~N}$ were distilled over $\mathrm{CaH}_{2}$. Conversions were determined by GC/MS and the enantiomeric excesses by $\mathrm{GC}$ analysis using a chiral column (Chiraldex, G-TA (gamma cyclodextrin trifluoroacetyl), $30 \mathrm{~m} \times 0.25 \mathrm{~mm}$ ).

\section{Polymer-bound salen-ligand 3}

DCC (46 mg, $0.22 \mathrm{mmol}$ ) was added to a suspension of PS-polymer (82 mg), compound $2 \mathbf{b}$ (120 $\mathrm{mg}, 0.198 \mathrm{mmol})$, and DMAP (2 $\mathrm{mg}, 0.016 \mathrm{mmol})$ in dry $\mathrm{CH}_{2} \mathrm{Cl}_{2}(2 \mathrm{~mL})$. The reaction mixture was stirred for $48 \mathrm{~h}$ at room temperature before the polymer was filtered off and washed with 
$\mathrm{MeOH}(2 \mathrm{~mL}), \mathrm{EtOH}(2 \mathrm{~mL}), \mathrm{THF} / \mathrm{H}_{2} \mathrm{O}$ 1:1 $(2 \mathrm{~mL})$, and $\mathrm{MeOH}(2 \mathrm{~mL})$ and then dried under vacuum overnight, resulting in a bright yellow polymer containing $2.296 \% \mathrm{~N}$, corresponding to $0.820 \mathrm{mmol}$ ligand/g of polymer.

\section{Polymer-bound Ti-salen complex 4}

Polymer-bound salen ligand 3 (40 mg, $0.033 \mathrm{mmol}$ ) was suspended in dry dichloromethane (1 $\mathrm{mL})$. $\mathrm{TiCl}_{4}(0.033 \mathrm{mmol}, 33 \mu \mathrm{L} 1 \mathrm{M}$ dichloromethane solution) was added and the resulting mixture was stirred under $\mathrm{N}_{2}$ for $2 \mathrm{~h}$ before addition of phosphate buffer $(\mathrm{pH}=7)$. The reaction suspension was stirred for additionally $2 \mathrm{~h}$ before the solvent was removed by filtration and the solid washed with dichloromethane. After drying under vacuum a yellow solid was obtained (44 $\mathrm{mg})$.

General procedure for enantioselective addition of TMSCN to benzaldehyde catalyzed polymeric Ti-salen complex 4

A solution containing benzaldehyde $(0.26 \mathrm{mmol}, 26 \mu \mathrm{L})$ and TMSCN $(0.3 \mathrm{mmol}, 40 \mu \mathrm{L})$ in dry dichloromethane $(1 \mathrm{~mL})$ was prepared. The stock solution was flowed trough the microreactor containing the polymeric Ti-salen complex $4(20 \mathrm{mg})$ by using a syringe pump. The reaction solution was collected, diluted with diethyl ether, filtered trough silica, and analyzed by GC-MS.

General procedure for enantioselective addition of acetyl cyanide to benzaldehyde catalyzed by polymeric Ti-salen complex 4 and triethylamine

A solution containing benzaldehyde $(5.20 \mathrm{mmol}, 52 \mu \mathrm{L})$, acetyl cyanide $(1.04 \mathrm{mmol}, 74 \mu \mathrm{L})$, and triethylamine $(0.0104 \mathrm{mmol}, 1.4 \mu \mathrm{L})$ in dry dichloromethane $(2 \mathrm{~mL})$ was prepared. The stock solution was flowed trough the microreactor containing the polymeric Ti-salen complex 4 (20 $\mathrm{mg}$ ) by using a syringe pump. The reaction solution was collected, diluted with diethyl ether, filtered trough silica, and analyzed by GC-MS.

\section{Acknowledgements}

This work was supported by the Swedish Foundation for Strategic Research

\section{References and Notes}

1. (a) Dioos, B. M. L.; Vankelecom, I. F. J; Jacobs, P. A. Adv. Synth. Catal. 2006, 348, 1413. (b) Heitbaum, M.; Glorius, F.; Escher, I. Angew. Chem. Int. Ed. 2006, 45, 4732. (c) Bräse, S.; Lauterwasser, F.; Ziegert, R. E. Adv. Synth. Catal. 2003, 345, 869. (d) Fan, Q.H.; Li, Y.-M.; Chan, A. S. C. Chem. Rev. 2002, 102, 3385. 
2. For some examples of the use of solid-supported catalysts in microfluidic devices, see: (a) Greenway, G. M.; Haswell, S. J.; Morgan, D. O.; Skelton, V.; Styring, P. Sens. Actuators. B 2000, 63, 153. (b) Kirschning, A.; Altwicker, C.; Dräger, G.; Harders, J.; Hoffmann, N.; Hoffmann, U.; Schönfeld, ; Solodenko, W.; Kunz, U. Angew. Chem. Int. Ed. 2001, 40, 3995. (c) Kobayashi, J.; Mori, Y.; Okamoto, K.; Akiyama, R.; Ueno, M.; Kitamori, T.; Kobayashi, S. Science 2004, 304, 1305. (d) Baxendale, I. R.; GriffithsJones, C. M.; Ley, S. V.; Tranmer, G. K. Chem. Eur. J. 2006, 12, 4407. (e) Uozumi, Y.; Yamada, Y. M. A.; Beppu, T.; Fukuyama, N.; Ueno, M.; Kitamori, T. J. Am. Chem. Soc. 2006, 128, 15994.

3. (a) Fletcher, P. D. I.; Haswell, S. J.; Pombo-Villar, E.; Warrington, B. H.; Watts, P.; Wong, S. Y. F.; Zhang, X. Tetrahedron 2002, 58, 4735. (b) Watts, P.; Haswell, S. J. Chem. Soc. Rev. 2005, 34, 235. (c) Brivio, M.; Verboom, W.; Reinhoudt, D. N. Lab Chip, 2006, 6, 329. (d) Geyer, K.; Codée, J. D. C.; Seeberger, P. H. Chem. Eur. J. 2006, 12, 8434; (e) Watts, P.; Wiles, C. Chem. Commun. 2007, 443. (f) Ahmed-Omer, B.; Brandt, J. C.; Wirth, T. Org. Biomol. Chem. 2007, 5, 733. (g) Watts, P.; Wiles, C. Org. Biomol. Chem. 2007, 5, 727. (g) Mason, B. P.; Price, K. E.; Steinbacher, J. L.; Bogdan, A. R.; McQuade, D. T. Chem. Rev. 2007, 107, 2300.

4. (a) Watts, P.; Haswell, S. J. Curr. Opin. Chem. Biol. 2003, 7, 380. (b) Comer, E.; Organ, M. G. Chem. Eur. J. 2005, 11, 7223.

5. (a) Jänisch, K.; Hessel, V.; Löwe, H.; Baerns, M. Angew. Chem. Int. Ed. 2004, 43, 406.

(b) Thayer, A. M. Chem. Eng. News 2005, 83, 43.

6. (a) Wiles, C.; Watts, P.; Haswell, S. J.; Pombo-Villar, E. Lab Chip 2004, 4, 171. (b) Matsuoka, S.; Hibara, A.; Ueno, M.; Kitamori, T. Lab Chip 2006, 6, 1636.

7. For recent examples of metal-catalyzed reactions performed in microfluidic devices, see: (a) Fukuyama, T.; Shinmen, M.; Nishitani, S.; Sato, M.; Ryu, I. Org. Lett. 2002, 4, 1691. (b) He, P.; Haswell, S. J.; Fletcher, P. D. I. Lab Chip 2004, 4, 38. (c) Comer, E.; Organ, M. G. J. Am. Chem. Soc. 2005, 127, 8160. (d) Saaby, S.; Rahbek, K. K.; Ladlow, M.; Ley, S. V. Chem. Commun. 2005, 2909.

8. (a) Jönsson, C.; Lundgren, S.; Haswell, S. J.; Moberg, C. Tetrahedron 2004, 60, 10515.

(b) de Bellefon, C.; Lamouille, T.; Pestre, N.; Bornette, F.; Pennemann, H.; Neumann, F.; Hessel, V. Catal. Today 2005, 110, 179. (c) Hamberg, A.; Lundgren, S.; Wingstrand, E.; Moberg, C.; Hult, K. Chem. Eur. J. 2007, 13,4334.

9. Belder, D.; Ludwig, M.; Wang, L.-W.; Reetz, M. T. Angew. Chem. Int. Ed. 2006, 45, 2463.

10. Hamberg, A.; Lundgren, S.; Penhoat, M.; Moberg, C.; Hult, K. J. Am. Chem. Soc. 2006, 128, 2234.

11. Belokon, Y. N.; Caveda-Cepas, S. B.; Ikonnikov, S.; Khrustalev, V. N.; Larichev, V. S.; Moscalenko, M. A.; North, M.; Orizu, C.; Tararov, V. I.; Tasinazzo, M.; Timofeeva, G. I.; Yashkina, L. V. J. Am. Chem. Soc. 1999, 121, 3968. 
12. (a) Belokon', Y. N.; Blacker, A. J.; Clutterbuck, L. A.; North, M. Org. Lett. 2003, 5, 4505. (b) Belokon', Y. N.; Blacker, A. J.; Carta, P.; Clutterbuck, L. A.; North, M. Tetrahedron 2004, 60, 10433.

13. (a) Lundgren, S.; Wingstrand, E.; Penhoat, M.; Moberg, C. J. Am. Chem. Soc. 2005, 127, 11592. (b) Wingstrand, E.; Lundgren, S.; Penhoat, M.; Moberg, C. Pure Appl. Chem. 2006, 78, 409. (c) Lundgren, S.; Wingstrand, E.; Moberg, C. Adv. Synth. Catal. 2007, 349, 364.

14. Annis, D. A.; Jacobsen, E. N. J. Am. Chem. Soc. 1999, 121, 4147.

15. Reger, T. S.; Janda, K. D. J. Am. Chem. Soc. 2000, 122, 6929.

16. Ihre, H.; Larsson, A. US Pat. 7060187 B2, 2006.

17. Yang, W.-B.; Fang, J.-M. J. Org. Chem. 1998, 63, 1356.

18. Bevinakatti, H. S.; Banerji, A. A.; Newadkar, R. V. J. Org. Chem. 1989, 54, 2453. 